\title{
A STUDY OF CHANGES IN QTC INTERVAL IN ECG IN CIRRHOSIS OF LIVER
}

\author{
V. C. Srinivas Reddy ${ }^{1}$ Jyotirmayi Boddu²
}

${ }^{1}$ Assistant Professor, Department of General Medicine, Andhra Medical College, Visakhapatnam, Andhra Pradesh.

${ }^{2}$ Assistant Professor, Department of General Medicine, Andhra Medical College, Visakhapatnam, Andhra Pradesh.

\begin{tabular}{l}
\hline ABSTRACT \\
\hline BACKGROUND \\
Impaired myocardial contractility as well as electrophysiological abnormalities in cirrhosis is called "Cirrhotic cardiomyopathy." \\
This chronic cardiac dysfunction characterised with electrophysiological abnormalities, such as prolongation of the QT interval \\
occurring in the absence of any other cardiac disease.
\end{tabular}

\section{AIM OF THE STUDY}

To assess changes in QTc interval in ECG in patients of cirrhosis of liver.

\section{MATERIALS AND METHODS}

In this observational study, 50 ambulatory hemodynamically stable patients admitted in Department of General Medicine, King George Hospital, Visakhapatnam, who were diagnosed to have cirrhosis of the liver were included in the study. A detailed history and thorough physical examination was performed with special reference to cardiovascular system. Age and gender matched control group was selected for comparison with the patients. All participants in the study were subjected to electrocardiography.

\section{RESULTS}

Males 38(76\%), Females 12(24\%), QTc prolongation - 21 vs 1 in cirrhotic patients compared to controls, $p<0.0001$. Between alcoholic cirrhotics and non-alcoholic cirrhotics - QTc prolongation - 38.89\% vs 43.75\% ( $\mathrm{p}=0.74)$.

\section{CONCLUSIONS}

Prolonged QTc was significantly more frequent in cirrhotic patients compared to that of the controls.

\section{KEYWORDS}

QTc Interval, Cirrhosis of Liver, Cardiomyopathy.

HOW TO CITE THIS ARTICLE: V. C. Srinivas Reddy, Jyotirmayi Boddu. "A Study of Changes in Qtc Interval in ECG in Cirrhosis of Liver." Journal of Evolution of Medical and Dental Sciences 2015; Vol. 4, Issue 102, December 21; Page: 16759-16760, DOI: $10.14260 /$ jemds/2015/2510

\section{INTRODUCTION}

Cirrhosis of liver results in disorganisation of the lobular and vascular architecture. Portal hypertension develops due to resistance to blood flow through the liver, thereby increase in portosystemic collaterals which pass the liver.

One of the manifestations of portal hypertension is hyperdynamic circulatory state due to activation of neurohumoral pathways that stimulate renal sodium retention, expansion of plasma volume. This hyperdynamic circulatory syndrome is associated with a variety of cardiovascular alterations.[1] In addition, the heart in patients with cirrhosis presents with structural and functional abnormalities that have been termed cirrhotic cardiomyopathy.[2],[3]

"Cirrhotic cardiomyopathy" is a chronic cardiac dysfunction, characterised by blunted contractile responsiveness to stress and altered diastolic relaxation with electrophysiological abnormalities, such as prolongation of the QT interval, all occurring in the absence of any other cardiac disease. ${ }^{[4,5]}$

Financial or Other, Competing Interest: None.

Submission 10-11-2015, Peer Review 11-11-2015,

Acceptance 19-11-2015, Published 19-12-2015.

Corresponding Author:

Dr. V. C. Srinivas Reddy,

Assistant Professor in Medicine,

Andhra Medical College,

Visakhapatnam-530002,

Andhra Pradesh.

E-mail:drvcsr@yahoo.co.in

DOI:10.14260/jemds/2015/2510
Electrophysiological changes like prolonged repolarisation and impaired cardiac excitation - contraction coupling have been demonstrated in these patients.[6,7] Repolarisation prolongation is manifested by a prolonged QT interval on the electrocardiogram. Prolongation of QT interval can be associated with an increased risk of certain ventricular arrhythmias, particularly the "Torsade de pointes" type of ventricular tachycardia. Rate-corrected of the QT ( $>440 \mathrm{msec}$ ) is found in $30 \%-60 \%$ of patients with cirrhosis.[6,7]

The exact mechanism leading to these electrophysiological changes is unclear. In clinical studies, severity of liver disease and circulatory dysfunction are related to prolonged QT interval. Moreover, these changes disappear after liver transplantation in most patients. $[6,7]$

\section{AIM OF THE STUDY}

To assess the prevalence of prolonged QTc interval in ECG in patients with cirrhosis of liver.

\section{MATERIALS AND METHODS \\ Inclusion Criteria}

The present study was an observational study conducted in King George Hospital of Andhra Pradesh. Fifty ambulatory hemodynamically stable patients of cirrhosis of liver irrespective of etiology were selected for the study. Age and gender matched control group was selected for comparison with the patients.

All were normal on clinical examination and did not have risk factors for cardiovascular, lung disease, any medications or acute illness. 


\section{Exclusion Criteria}

Anemia, Hypertension, Diabetes, Dyslipidemia, primary cardiac or pulmonary disease, GI bleed within the previous 3 months, those on B-blocker within the previous 3 weeks, heart disease, those with intercurrent illness and those who were critically ill were excluded from the study.

\section{RESULTS}

\section{Age and Gender}

Among total of 50 patients, 38 were male and 12 were female patients. Out of 50 controls, 32 were male and rest females (Table 1). The mean age of the patients and controls was 44 years and 47 years respectively.

\section{QTc Interval}

Out of 50 patients of liver cirrhosis, 21 had prolonged QTc ( $>440 \mathrm{~ms}$ ) and 29 had normal QTc interval. Among controls only 1 person has prolonged QTc $(>440 \mathrm{~ms})$ (Table 2$)$.

The difference between cases $(21 / 50$ or $42 \%)$ compared to controls $(1 / 50$ or $2 \%)$ is statistically significant $(\mathrm{p}<0.0001)$.

\section{QTc Interval between Alcoholics and Non-Alcoholics}

Prolonged QTc interval was present in 7/18 (38.89\%) among alcoholic cirrhotics compared to $14 / 32$ (43.75\%) among nonalcoholic cirrhotics (Table 3 ). The difference is not statistically significant $(\mathrm{p}=0.74)$.

\section{DISCUSSION}

In this study, the mean age of the patients was comparable with the control group.

The main electrocardiographic change in cirrhosis is a prolongation of the QT interval adjusted for heart rate. Our study had QTc prolongation of $42 \%$ vs $2 \%$ in patients vs controls. This is comparable to the findings of Bernardi et al., where QTc was prolonged above $440 \mathrm{~ms}$ in $46.8 \%$ of patients and $5.4 \%$ of control subjects $(\mathrm{P}<001) .{ }^{(6)}$

The difference in the prevalence of prolongation of QTc among alcoholics and non-alcoholics is not statistically significant, similar to the findings noted by Bernardi et al.[6] This is unrelated to the aetiology of the liver disease and effect of alcohol. [8,9]

A prolonged QTc interval is fundamentally due to a delayed repolarization phase, which is responsible for an increased risk of ventricular arrhythmias and sudden death.[10] More likely, a latent heart failure and cardiac dysfunction are present in some patients with cirrhosis, especially in those patients with a more deranged circulation. Although overt cardiac failure is uncommon in cirrhosis, unexpected cardiac deaths have occurred following surgery in patients with cirrhosis.[11-13) suggesting that better assessment of cardiac function is needed in these patients.

This study has excluded those with very advanced hepatic dysfunction and as only a few patients of hepatic cirrhosis present in the early stage, the results essentially represent the middle of the spectrum of the disease severity. This study included only a limited spectrum of the disease is one of the drawbacks of this study design.

\section{CONCLUSIONS}

Cardiac evaluation should be a pre-requisite in patients with cirrhosis undergoing stress like surgery, because the presence of cardiac involvement adds to the morbidity and mortality.

Further studies dedicated to this purpose are required to accurately delineate the extent of correlation between severity of hepatic dysfunction and cardiac changes in cirrhotics.

\section{REFERENCES}

1. Bosch J, Pizcueta P, Feu F, et al. Pathophysiology of portal hypertension.

Gastroenterol Clin North Am 1992;21:1-14.

2. Ma Z and Lee SS. Cirrhotic cardiomyopathy: getting to the heart of the matter. Hepatology 1996;24:451-9.

3. Moller S and Henriksen JH. Cirrhotic cardiomyopathy: a pathophysiological review of circulatory dysfunction in liver disease. Heart 2002;87:9-15 4.

4. Zambruni A, Trevisani F, Caraceni P, et al. Cardiac electrophysiological abnormalities in patients with cirrhosis. J Hepatol 2006;44:994-1002.

5. Møller S, Henriksen JH. Cardiovascular complications of cirrhosis. Gut 2008;57:268-78.

6. Bernardi M, Calandra S, Colantoni A, Trevisani F, Raimondo ML, Sica G, et al. Q-T interval prolongation in cirrhosis: prevalence, relationship with severity and etiology of the disease and possible pathogenetic factors. Hepatology 1998;27:28-34.

7. Bal JS, Thuluvath PJ. Prolongation of QTc interval: relationship with etiology and severity of liver disease, mortality and liver transplantation. Liver Int 2003;23:243-248.

8. Alexander J, Mishra P, Desai N, Ambadekar S, Gala B, Sawant P. Cirrhotic cardiomyopathy: Indian scenario. J Gastroenterol Hepatol 2007;22:395-9.

9. Lazzeri C, Lavilla G, Laffi G, Vecchiarino S, Gambilonghi F, Gentilini $\mathrm{P}$, et al. Autonomic regulation of heart rate and QT interval in non-alcoholic cirrhosis with ascites. Digestion 1997;58:580-6.

10. Tan HL, Hou CJ, Lauer MR, et al. Electrophysiologic mechanisms of 29. The long QT interval syndromes and torsade de pointes. Ann Intern Med 1995;122(9):701-14.

11. Rayes N, Bechstein WO, Keck H, Blumhardt G, Lohmann $R$ and Neuhaus P. (1995) Causes of death after liver transplantation: an analysis of 41 cases in 382 patients. Zentralbl Chir 120, 435-8.

12. Lebrec D, Giuily N, Hadenque A, et al. (1996) Transjugular intrahepatic portosystemic shunt: comparison with paracentesis in patients with cirrhosis and refractory ascites: a randomized trial. J Hepatol 25, 135-44.

13. Franco D, Vons C, Traynor O, et al. (1988). Should portocaval shunt be reconsidered in the treatment of intractable ascites in cirrhosis? Arch Surg 123, 987-91.

\begin{tabular}{|c|c|c|}
\hline & CASES & CONTROLS \\
\hline AGE (Mean) & 44.26 & 47.14 \\
\hline MALES & 38 & 32 \\
\hline FEMALES & 12 & 18 \\
\hline \multicolumn{2}{|c|}{ Table 1: Age and Gender Distribution } \\
\hline
\end{tabular}

\begin{tabular}{|c|c|c|}
\hline Study Subjects & Cases & Controls \\
\hline QTc Prolonged $(>440 \mathrm{msec})$ & 21 & 1 \\
\hline QTc Normal $(<440 \mathrm{msec})$ & 29 & 49 \\
\hline \multicolumn{2}{|c|}{ Table 2: QTc Interval between Cases and Controls } \\
\hline
\end{tabular}

\begin{tabular}{|c|c|c|c|}
\hline Cases & $\begin{array}{c}\text { QTc- } \\
\text { Prolonged }\end{array}$ & QTc- Normal & Total \\
\hline ALCOHOLICS & 7 & 11 & 18 \\
\hline $\begin{array}{c}\text { NON- } \\
\text { ALCOHOLIC }\end{array}$ & 14 & 18 & 32 \\
\hline TOTAL & $\mathbf{2 1}$ & $\mathbf{2 9}$ & $\mathbf{5 0}$ \\
\hline Table 3: QTc Interval - Alcoholics Vs Non-Alcoholics \\
\hline
\end{tabular}

